KOÇ UNIVERSITY-TÜSİAD ECONOMIC RESEARCH FORUM WORKING PAPER SERIES

\title{
ARE LABOR FORCE PARTICIPATION RATES REALLY NON-STATIONARY? EVIDENCE FROM THREE OECD COUNTRIES
}

\author{
Zeynel Abidin Ozdemir \\ Mehmet Balcilar \\ Aysit Tansel
}

Working Paper 1223

August 2012

KOÇ UNIVERSITY-TÜSİAD ECONOMIC RESEARCH FORUM

Rumelifeneri Yolu 34450 Sariyer/Istanbul 


\title{
Are Labor Force Participation Rates Really Non-Stationary? Evidence from Three OECD Countries
}

\author{
Zeynel Abidin Ozdemir \\ Department of Economics, Gazi University, Besevler, 06500, Ankara, TURKEY \\ e-mail: zabidin@gazi.edu.tr, Phone: +(90) 3122161115 \\ Fax: +(90) 3122132036 \\ Mehmet Balcilar \\ Department of Economics, Eastern Mediterranean University, Gazimagosa, Turkish Republic of North Cyprus \\ e-mail: mehmet.balcilar@emu.edu.tr, Phone: +90 392630 1548×1548, Fax: +90 3923651017 \\ Aysit Tansel* $^{*}$ \\ Department of Economics, Middle East Technical University, 06531, Ankara, TURKEY. \\ Institute for Study of Labor (IZA), Bonn, GERMANY \\ Economic Research Forum (ERF), Cairo, EGYPT \\ e-mail: atansel@metu.edu.tr, Phone: +(90) 31221020 57, Fax: +(90) 3122107964
}

\begin{abstract}
This paper shows that the structural breaks are an important characteristic of the monthly labor force participation rate (LFPR) series of Australia, Canada and the USA. Therefore we allow for endogenously determined multiple structural breaks in the empirical specifications of fractionally integrated ARMA model. The findings indicate that contrary to the previous research the LFPRs of Australia, Canada and the USA are stationary implying that the informational value of the unemployment rates about the behavior of labor markets and the causes of joblessness are useful.
\end{abstract}

Key words: Labor Force Participation Rates; Structural Change; Stationarity.

JEL classification: C22; E24; J21.

\footnotetext{
* We would like to thank Vincent Ferrao, Steve Hipple and Mark R. Killingsworth who shared their views on labor force participation rates with us generously. Any errors are our own.
} 


\section{Introduction}

Economists have a long history of interest in an understanding of how labor markets function. This interest is partly due to the fact that long-run impact of economic policy depends on labor market characteristics. The theory of labor market hysteresis implies that one-time shocks to the labor market have permanent effects. In order to test the theory of labor market hysteresis many researchers concentrated on investigating the time series properties of unemployment rates. However, the examination of only the unemployment rates may not allow healthy inferences about the labor market characteristics if labor force participation rates are changing over time (Murphy and Topel, 1997) for instance due to added worker and discouraged worker effects over the course of business cycles. Then, the question is to check whether the participation rates are changing in a stationary or in a nonstationary way. Stationarity of participation rates implies one-to-one relationship between time series properties of unemployment and employment rates while non-stationarity of the participation rates may undermine the informational value of the unemployment rates about the labor market characteristics. Therefore, a proper analysis of the functioning of labor markets should start with investigating the properties of participation rates which have attracted the attention of several labor economists recently such as Gustavsson and Österholm (2006) and Madsen et al.(2008).

The aim of this paper is to investigate whether rates in Australia, Canada and the USA are non-stationary so as to undermine the informational value of unemployment rates. For this purpose we examine the properties of the participation rates in these countries. An examination of the evolution of the participation rates indicate that they are characterized by an increasing trend over time due to the massive increase in the female labor force participation rates especially in the 1960s. The second important characteristic of these series is the occurrence of several structural breaks such as level shifts and trend breaks. These structural break points may have been caused by business cycles or changes in survey applications. For these reasons we argue that structural breaks must be taken into account while investigating the non-stationarity properties of the labor force participation rates of the Australia, Canada and the USA. Using a "battery” of univariate unit root test Gustavsson and Österholm (2006) find that the labor force participation rates in Australia, Canada and the USA are all non-stationary. However, they ignore completely the possibility of the structural breaks in these series. Madsen et al. (2008) do indeed take into account the possibility of the 
structural breaks in the labor force participation rates of the G-7 countries. They first use a unit root test with a non-linear threshold. They find mean-reversion albeit sensitive to regime shifts. Next they investigate trend reversion properties of the same series by using a lagrange multiplier unit root test with one or two structural breaks in the intercept and slope. They conclude that "there is at best mixed evidence" (p. 168) on the stationarity of the labor force participation rates of the G-7 countries including Canada and the USA.

In this paper we first examine the labor force participation rates (LFPR henceforth) for Australia, Canada and the USA and endogenously determine several structural break points in the series and discuss their possible causes. Next, we employ a class of generalized univariate processes, called fractionally integrated processes (Granger and Joyeux, 1980; Hosking, 1981) with structural breaks ${ }^{1}$. They are flexible enough to capture the mean-reverting dynamics in the series. Therefore, they allow modeling the Labor force participation rate movements over time better than the standard time series models. In order to examine the possibility of mean reversion, we use a test developed by Robinson (1994) which permits testing $\mathrm{I}(d)$ hypothesis allowing for breaks at known times.

The results of this paper indicate that the LFPR series of Australia, Canada, and the USA are mean-reverting when the time trend is taken into account. However, the level shifts and/or trend breaks in the LFPR series significantly reduce their order of integration. Unlike the previous papers this paper uses Fractionally Integrated Autoregressive Moving Average (ARFIMA) disturbance processes where the lag-lengths are empirically determined and the structural break points are endogenously determined. Thus, we are unequivocally able to establish stationarity of the series contrary to the findings of Gustavsson and Österholm (2006) and Madsen et al.(2008). Our findings give credit to the widespread use of unemployment rates to draw sound inferences about the labor market characteristics and that the unemployment rate is a useful indicator of joblessness.

The rest of this paper is organized as follows. The main properties of the LFPRs in Australia, Canada and the USA are given in Section 2. Section 3 provides a discussion of the

\footnotetext{
${ }^{1}$ Perron (1989) was the first to indicate that a series may show apparent non-stationarity due to neglected structural breaks. A massive literature on the implications of structural breaks developed post Perron (1989). It's also true that a very important literature on various implications for many economic and financial questions developed post Granger and Joyeux (1980) and Hosking (1981).
} 
methodology used in evaluating the order of integration of the LFPR series. Section 4 presents the empirical results. Last section provides the concluding remarks.

\section{Data Properties}

Seasonally adjusted monthly data on the LFPR for Australia, Canada and the USA are used. LFPR represent the proportion of the population that is in the labor force which comprises all persons classified as employed or unemployed - but actively looking for a job in accordance with certain criteria. These criteria may differ somewhat among the three countries. For example, while the total population considered is 15 years and older in Australia and Canada and it is 16 years and older in the USA. These monthly data start with February 1978, January 1976 and January 1951 respectively for Australia, Canada and the USA and end in July 2008. Figures 1, 2 and 3 pertain to Australia, Canada and the USA, respectively. Panel A in these figures presents the time series plots of the LFPR of the three countries.

This paper considers the LFPRs series of Australia, Canada and the USA. Any LFPR series may exhibit some apparent or real structural breaks. Some of the factors that might be at work in generating apparent or real breaks are as follows ${ }^{2}$ :

i-) Methodological changes: These may involve changes in survey methods, concepts, definitions, etc. Sometimes, the series changes because the survey organization adopts different conventions and procedures. For example, they may change the definition of unemployment, or stop counting persons age 14-15, as the USA did in 1967.

ii-) Legislative changes: These may involve changes in tax and transfer programs and policies towards welfare recipients, etc. For example, Australia adopted a form of "equal pay for work of equal value" in 1969 with major amendments to it in 1972 (Lyons and Smith, 2008). This may have affected employment opportunities for women, and, thus, the labor force participation rate $^{3}$. Likewise, overtime the USA has expanded disability programs,

\footnotetext{
${ }^{2}$ Mark R. Killingsworth was very kind to point out to us the possible factors that may be behind the structural breaks in the LFPR series.

${ }^{3}$ Since its inception, the Australian policy approach to gender pay equity reform has been by way of labor law measures whereby centralized tribunal grants pay increases on an industry bases. In contrast to this in the
} 
which has resulted in a decline in male participation. She has also changed both the benefit levels and the eligibility requirements for Social Security payments which resulted in a decline in participation rates in older age groups. Most of the decline in the participation of older Americans is attributed to rising social security wealth. Anderson et al. (1999) found that about a quarter of the reduction in men's full-time employment during the 1969-1989 period was due to employer pension plans social security together. Gross replacement ratio increased from 19 to 41 in Australia, 31 to 56 in Canada and 39 to 56 in the USA over the 1961-1995 period (Ingles, 2000:30). Although the Australian social security system is very different from that of the USA the similar comments apply there as well (Ingles, 2000:19).

iii-) Compositional changes: These may involve changes in the components of the aggregate. For example, the LFPRs, particularly over the long time periods we consider is likely to behave quite differently depending on changes within the aggregate. Two very important compositional changes were the unprecedented increase in the female labor force participation and some declines in the male labor force participation, so that in all three countries we consider labor force has become more "feminized". For the comparative purposes consider the following changes that took place from 1978 to 2004 part of our sample period. In Australia the female LFPR increased from 44 percent in 1978 to 56 percent in 2004 while the male LFPR decreased from 79 percent in 1978 to 71 percent in 2004. During the same period the female LFPR for Canada increased from 48 percent to 62 percent while the male LFPR decreased from 78 to 73 percent. Similar changes occurred in the USA. In the USA, female LFPR was only 35 percent in 1951. Over the period of 1978-2004 while female LFPR increased from 50 to 59 percent the male LFPR decreased from 78 to 73 percent. Over this period the largest increase in female LFPR occurred in Canada with 14 percentage points and the largest decrease in male LFPR occurred in Australia with 9 percentage points. Currently the female LFPR is about 3-6 percentage points higher in Canada than in Australia and the USA. The increase in female labor force participation is responsible for the increasing trend in the labor force participation rates over the period of observation for all three countries considered in this paper.

$i v$-) Cyclical and secular factors: Some of the dips and peaks could be a consequence of business cycle factors, while others may at least to some extent be the result of long-run 
factors such as increasing wage premiums for high-skill labor and falling relative or even absolute wages for low-skill labor, combined with general upgrading of the skill-level as measured by, say, education of the labor force.

Over the period of observation 1978:2 to 2004:11 for Australia there were some methodological changes in the labor force survey. For instance from April 1986 the definition of employed people was changed to include unpaid family workers who worked 1-14 hours per week in a family business or on a farm. In August 1996, telephone interviewing was introduced. From April 2001 a redesigned questionnaire has been used at which date the core labor force series were revised back to April 1986 (Australian Bureau of Statistics, 2008). The effects of these methodological changes are not much visible on Figure 1 except that of the April 1986. During the period of observation for Australia there were two major recessions: One was around 1982 and the other was around 1991 (Australian Bureau of Statistics, 2004). The labor market impact of these recessions may have started somewhat earlier than these dates. Therefore we introduce one level and two trend shift dummy variables: one in March 1985 which takes into account both the methodological change and the recession and the other in July 1990 which takes into account the recession. These dummy variables are formally defined in Section 4.

Over the period of observation 1976:1 to 2004:11 for Canada there were some methodological changes in the labor force survey. A new labor force survey questionnaire was introduced in 1997 together with computer assisted interviewing. Since 2004 telephone interviews are employed. In January 2000 a new estimation method was introduced. Over time other improvements were introduced however, the data was revised back to 1976:1, so that no clear breaks due to methodological changes are observed (Statistics Canada, 2006). Therefore the time series is consistent and comparable. As it is in the case of Australia, there were two major recessions in Canada. One was in the early 1980's and the other was in the early 1990's both of which were responsible for the ensuing declines in the LFPR. A jobless growth period with a decline in LFPR that followed the early 1990 recession continued for a relatively long period of time until 1996:3 at which point an increasing trend has started. From 2003 onwards a relatively slower growth in the LFPR has been attributed to several reasons such as the shortage of workers and an aging labor force. Accordingly we introduced three level and trend shift dummy variables on October, 1981; January, 1990 and March, 1996, all of which are defined formally in Section 4. 
A number of methodological and conceptual changes have been implemented over the years in the Current Business Survey (CBS) of the USA which is the source of our data. Some of the most important changes include the following. In 1945 the questionnaire was changed and in 1953 the current rotation system was adopted. The change in survey reference week in 1955 and the employment definition in 1957 was followed in 1967 by substantive changes to the definitions of employed and unemployed together with a rise in lower age limit from 14 to 16 years and start of information collection on discouraged workers. However, the series are revised backwards to provide consistent information. A redesigned questionnaire and computer assisted interviewing were introduced in 1994 and the identification of the discouraged workers and part-time employed were tightened. Furthermore, there were periodic revisions as a result of employing the results of new censuses and due to changes in the estimation methods. These were followed by backwards revisions to enable comparability. Inclusion of Alaska and Hawaii in 1960, large inflow of Vietnamese refugees in 1975 and expansions of the sample in 1978 all affected the estimates of the levels of the totals and some components but not the rates such as LFPR that we consider in this paper.

As it is observed in Panel (a) of Figure 3, over the 1950s and 1960s the LFPR of the USA was stagnant however with different means for these two periods. But, it rose rapidly over the 1970s and 1980s with the movement of the baby-boom generation (those born between 1946 and 1964 with the peak birth year 1957) into high-participation-rate ages and the increase in participation among women. After 2001 the overall participation rate entered a declining phase due to three factors. One, the first of the baby boomers entered age 55 in 2001 which is the beginning age of traditionally lower participation rates. Second, the dramatic increase in the female LFPR of the previous periods has also flattened out in recent years. Finally, the economic crises which began in March, 2001 caused a decline in LFPR. These and other issues are discussed by Toossi (2002) and Mosisa and Hipple (2006) in detail. Until 1962 there were several but short-lived economic down turns (Mosisa and Hipple, 2006). We have taken these into account by introducing two level and one trend shift dummy variables in 1955:9 and 1961:7. The two other major recessions were in early and late 1990s we have taken these into account by introducing a trend shift dummy in 1990:2 and level and trend shift dummies in 1999:11, all of which are defined formally in Section 4. 
Panel (b) in Figures 1, 2 and 3 gives the times series plot of the first difference of the LFPR series. Panel (c) shows the correlogram and its 95\% confidence interval of the level data. The autocorrelations in this panel show a clear pattern of slow decay and persistence in the level of participation rates in the three countries. Panel (d) provides the correlogram of the first differenced labor force participation series and its 95\% confidence interval. The first differenced series appear to be overdifferenced with large negative autocorrelations at one lag. Thus, the visual examinations in Figure 1, 2 and 3 indicate that LFPR for the three countries exhibit persistence and long memory properties. This will be tested in the next section.

Figure 1: Time Series Properties of LFPR for Australia
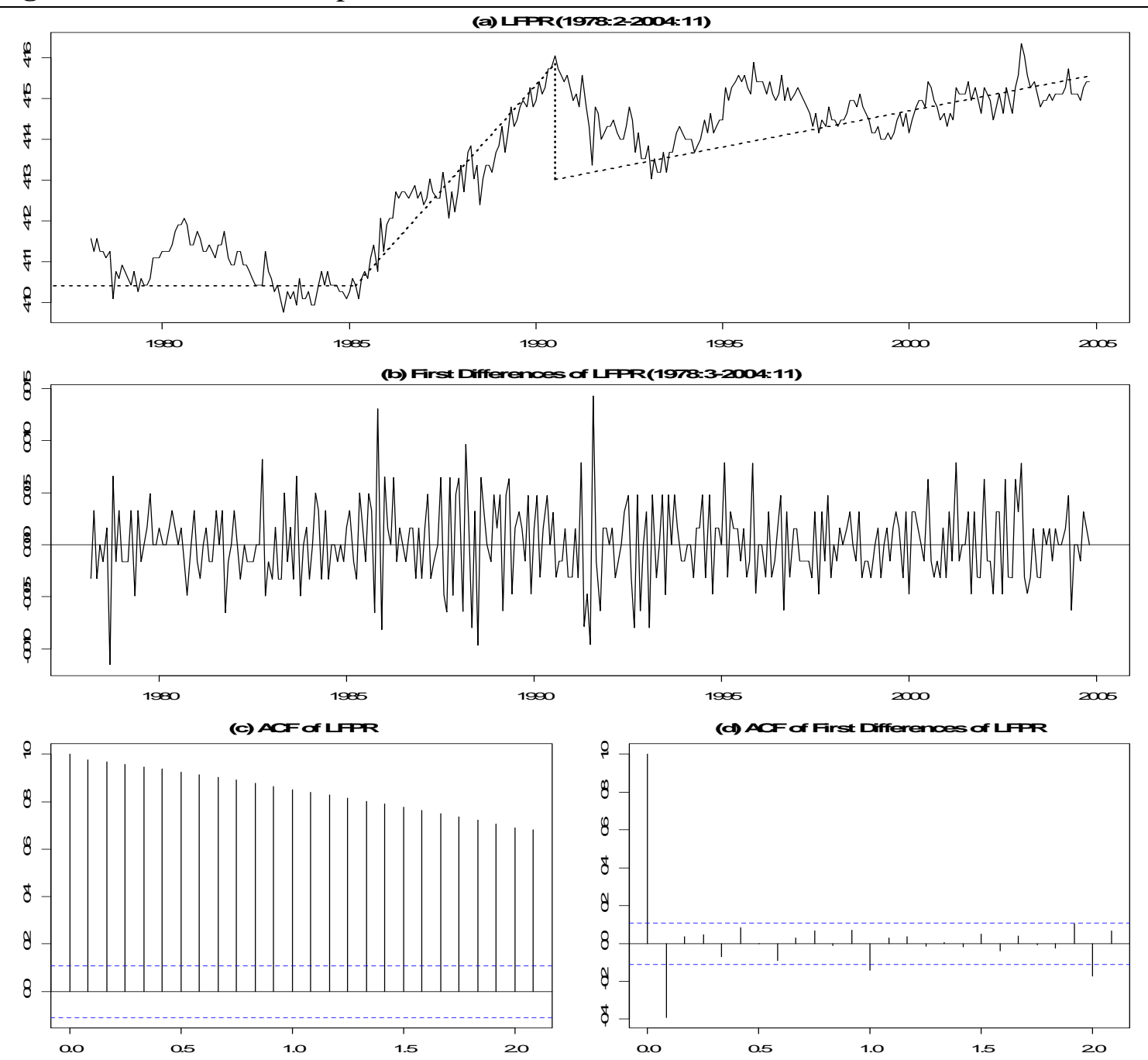
Figure 2: Figure 2: Time Series Properties of LFPR for Canada
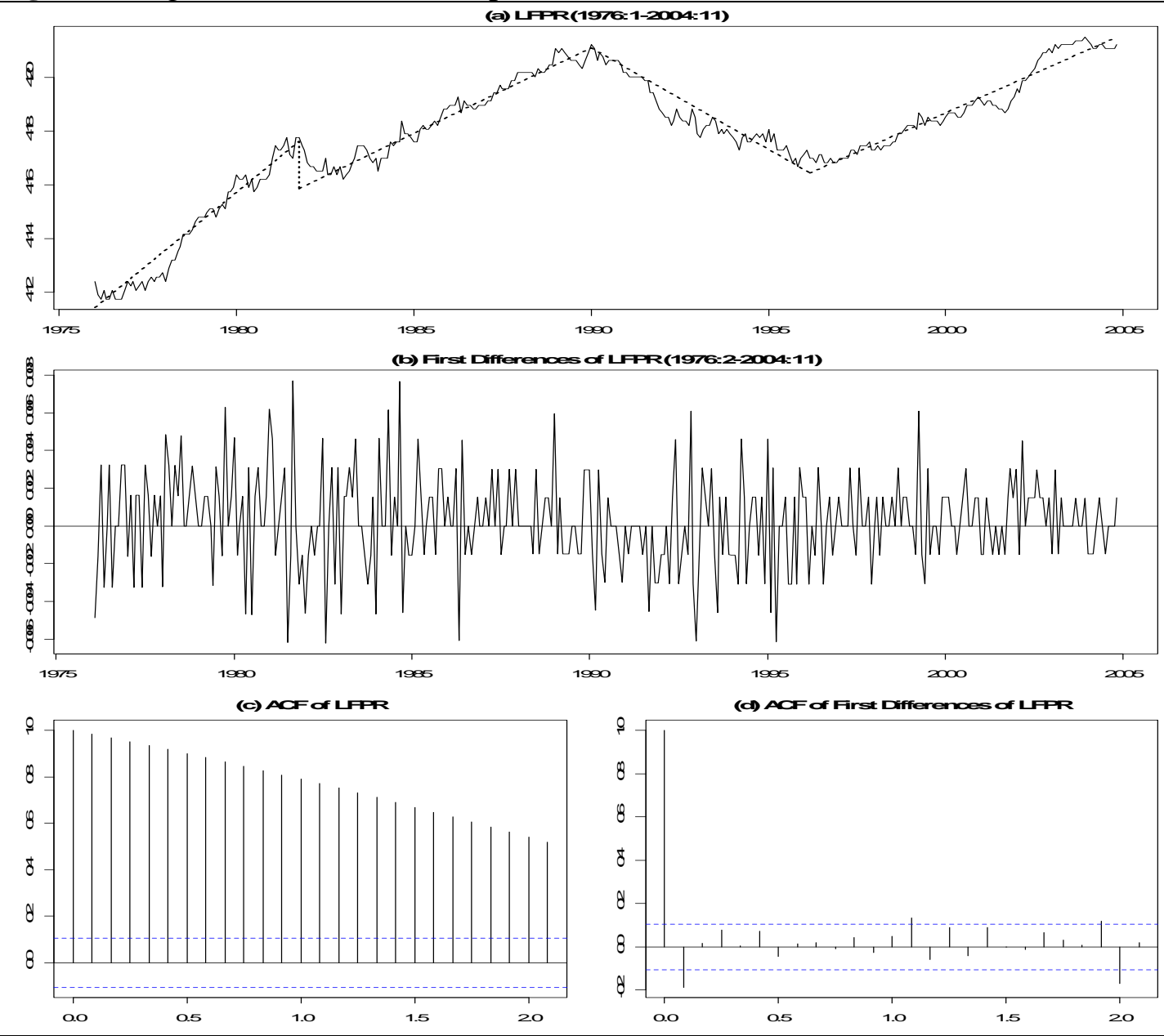
Figure 3: Time Series Properties of LFPR for the USA
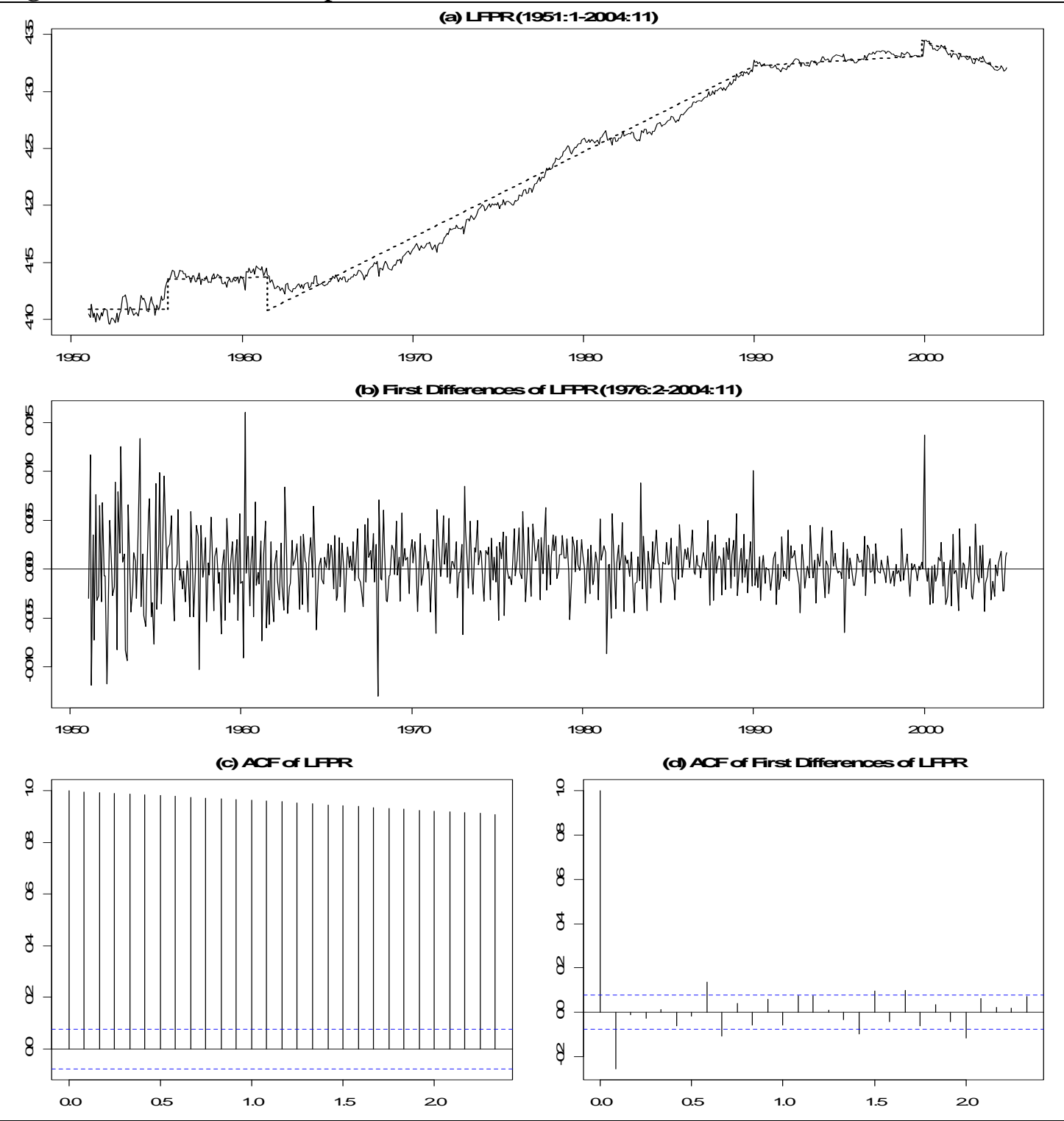

\section{Methodology}

\subsection{Testing for fractional integration with structural breaks}

Robinson (1994) developed a very general procedure for testing unit roots as well as other nonstationary alternatives. Unlike the other unit root tests (Dickey and Fuller, 1979; Phillips and Perron, 1998; and many others), which test for autoregressive (AR) unit roots, Robinson's procedure allows testing for fractional order of integration in addition to other appealing hypothesis. Klemes (1974), Künsch (1986), Hidalgo and Robinson (1996), Lobato and Savin (1997), Teverovsky and Taqqu (1997), Granger and Hyung (1999) and Diebold and Inoue 
(2001) draw our attention to the possibility of overstating the order of fractional integration when presence of structural breaks are not taken into account. This section provides a brief account of testing for fractional integration in the presence of unknown structural breaks due to Robinson.

Consider the multiple regression of the form

$$
y_{t}=\beta^{\prime} z_{t}+x_{t}, \quad t=1,2, \ldots, T
$$

where $y_{t}$ is the $k \times 1$ vector of time series we observe, $\beta$ is a $k \times 1$ vector of unknown parameters and $z_{t}$ is a matrix of observable variables which could include a constant, polynomials in time trend $(t)$ and structural break dummies as we would assume in the application section of this paper. The presence of such deterministic regressors does not effect the limiting null and local distributions of the Robinson test statistic, which is an advantage over other unit root tests. $T$ is the sample size. The regression errors $x_{t}$ are given by:

$$
(1-L)^{d} x_{t}=u_{t}
$$

where $L$ is the lag operator, $u_{t}$ is an $\mathrm{I}(0)$ process assumed to be a covariance stationary with spectral density function which is positive and finite at zero frequency. The order of integration $d$ is not restricted to integer values and can take any value on the real line. If $d \in(-$ $0.5,0.5)$, then $y_{t}$ is covariance stationary and invertible. When $d \in(-0.5,0), y_{t}$ is called antipersistent or intermediate memory. For $d \in(0,0.5), y_{t}$ is stationary. If $d \in[0.5,1)$, then $y_{t}$ is non-stationary. However, in both cases the process is mean reverting, as $d$ is less than one. On the other hand, for values of $d \geq 1, y_{t}$ is non-stationary and non-mean reverting, with the effect of shocks persisting forever (Granger and Joyeux, 1980; Hosking, 1981). We define the $(1-L)^{d}$ by means of the binomial expansion. In order to test the null hypothesis:

$$
H_{0}: d=d_{0},
$$

Robinson (1994) developed the following score test statistic:

$$
\hat{r}=\left(\frac{T^{1 / 2}}{\hat{\sigma}^{2}}\right) \hat{A}^{-1 / 2} \hat{a},
$$

where

$$
\hat{a}=-\frac{2 \pi}{T} \sum_{j=1}^{T-1} \psi\left(\lambda_{j}\right) g\left(\lambda_{j} ; \eta\right) I\left(\lambda_{j}\right), \quad I\left(\lambda_{j}\right)=\frac{1}{2 \pi T}\left|\sum_{t=1}^{T} \hat{u}_{t} e^{i \lambda_{j} t}\right|^{2}, \quad \lambda_{j}=\frac{2 \pi j}{T}
$$




$$
\begin{gathered}
\hat{\sigma}^{2}=(2 \pi / T) \sum_{j=1}^{T-1} g\left(\lambda_{j} ; \hat{\eta}\right) I\left(\lambda_{j}\right) . \\
\hat{A}=\frac{2}{T}\left(\sum_{j=1}^{T-1} \psi\left(\lambda_{j}\right) \psi\left(\lambda_{j}\right)^{\prime}-\sum_{j=1}^{T-1} \psi\left(\lambda_{j}\right) \hat{\xi}\left(\lambda_{j}\right)^{\prime} \times\left(\sum_{j=1}^{T-1} \hat{\xi}\left(\lambda_{j}\right) \hat{\xi}\left(\lambda_{j}\right)^{\prime}\right)^{-1} \times \sum_{j=1}^{T-1} \hat{\xi}\left(\lambda_{j}\right) \psi\left(\lambda_{j}\right)^{\prime}\right) \\
\hat{\xi}\left(\lambda_{j}\right)=\frac{\partial}{\partial \eta} \log g\left(\lambda_{j} ; \hat{\eta}\right), \quad \psi\left(\lambda_{j}\right)=\operatorname{Re}\left\{\frac{\partial}{\partial \gamma} \log \varphi\left(e^{-i \lambda_{j}} ; \gamma_{0}\right)\right\}
\end{gathered}
$$

where $I\left(\lambda_{j}\right)$ is the periodogram of $\hat{u}_{t}$. The parameter estimates $\hat{\eta}$ are obtained with the Whittle Maximum Likelihood (WML) method, which is obtained by

$$
\hat{\eta}=\arg \min _{\eta \in \Lambda} \frac{2 \pi}{T} \sum_{j=1}^{T-1} g\left(\lambda_{j} ; \eta\right) I\left(\lambda_{j}\right)
$$

where $g\left(\lambda_{j} ; \eta\right)$ is known function of the parametric spectral density of $u_{t}$. In this paper, the model for $u_{t}$ is restricted to the cases nested within an ARMA model with $g\left(\lambda_{j}, \eta\right)=2 \pi f\left(\lambda ; \sigma^{2}, \eta\right) / \sigma^{2}$ where $f\left(\lambda ; \sigma^{2}, \eta\right)$ is its spectral density. We first obtain the residuals as $\hat{x}=y_{t}-\hat{\beta}^{\prime} z_{t}$ where $\hat{\beta}$ is the Ordinary Least Square (OLS) estimate from equation (1). Then, the residuals $\hat{u}_{t}$ are obtained by fractional differencing from $\hat{u}_{t}=(1-L)^{d} \hat{x}_{t}$ which is obtained using the binomial expansion (Granger and Joyeux, 1980; Hosking, 1981).

Under certain regularity conditions and the null hypothesis given above Robinson (1994) showed that $\hat{r}$ approaches normal distribution with zero mean and variance one as $T$ approaches infinity. Note that this limiting distribution holds independently of the regressors included in $z_{t}$ and the various types of $\mathrm{I}(0)$ disturbances assumed for $u_{t}$, which includes the general weakly stationary ARMA models. Robinson shows that the test statistic $\hat{r}$ is efficient in the Pitman sense. An approximate one-sided test of $H_{0}: d=d_{0}$ is rejected in favor of $H_{1}: d>d_{0}\left(d<d_{0}\right)$ at the $100 \alpha \%$ level, when $\hat{r}>z_{\alpha},\left(\hat{r}<-z_{\alpha}\right)$ where $\alpha$ is the probability that a standard normal variate exceeds $Z_{\alpha}$. This and other versions of the Robinson (1994) test are used in empirical applications recently by Gil-Alana and Robinson $(1997,2001)$ and Gil-Alana (1999, 2001a, 2001b, 2002).

\section{Empirical Results}

The studies by Perron (1989, 1997), Zivot and Andrews (1992), Banerjee et al. (1992), Christiano (1992), Perron and Vogelsang (1992), Balcilar (1996), Lumsdaine and Papell (1997), Clemente et al. (1998), Ohara (1999) and Kapetanios (2005) showed that apparent 
non-stationarity may be caused by neglected structural changes. The stochastic permanent level shifts mimic the effect of a persistent shock. Therefore, the long memory models fitted to the data that has occasional level shifts may incorrectly find evidence of long memory. Several studies examined this possibility using models that allow level shifts. A more flexible model is the STOPBREAK model of Engle and Smith (1999), which models the level shifts as a component with stochastic permanent shifts. Bos et al. (1999) attempt to capture the effect of level shifts by inclusion of dummy variables. In this paper we show that the apparent non-stationarity found by Gustavsson and Österholm (2006) disappears when the fractional integrated process with endogenously determined structural breaks described by trend and level shifts are taken into account.

The apparent non-stationarity may be caused by neglected structural changes. In this paper, we examine the series of LFPR in Australia, Canada and the USA by allowing endogenously determined multiple structural breaks in a fractionally integrated process. We endogenously identified several structural break dates as reported in Table 1. Most of these breaks are a consequence of the business cycle factors that we observe during the sample period. Regression estimates of the parameters corresponding to the structural break dummies are very large. Therefore, these results are not reported, but are available from the authors upon request. The coefficients of these dummies in estimated regression models are all statistically significant at the 5 percent level or better.

Disturbances in equation (2) are assumed to be an $\operatorname{ARMA}(p, q)$ process. We estimate ARMA $(p, q)$ models with for LFPRs of each country. For each $d$ value, we choose $p, q$ lag lengths according to the Bayesian Information Criteria (BIC). The values of the BIC corresponding to different $p, q$ combinations are given in Table 2. The first column of the tables gives the values of $d$ under the null hypothesis. The columns correspond to the different assumptions for $z_{t}$ as indicated. The columns for $z_{t}=0$ and $z_{t}=1$ correspond to the cases of no deterministic term and only a constant term, respectively. $z_{t}=(1, t)$ corresponds to the case of a constant and a linear time trend term. $z_{1 t}, z_{2 t}$ and $z_{3 t}$ correspond to the dates described in Table 1. They include a constant and linear time trend along with level and trend shift dummies.

The apparent non-stationarity may be caused by neglected structural changes. In this paper, we examine the series of total LFPR in Australia, Canada and the USA by allowing endogenously determined multiple structural breaks in a fractionally integrated process. We 
endogenously identified several structural break dates as reported in Table 1. Most of these breaks are a consequence of the business cycle factors that we observe during the sample period. Regression estimates of the parameters corresponding to the structural break dummies are very large. Therefore, these results are not reported, but are available from the authors upon request. The coefficients of these dummies in estimated regression model are all statistically significant at the 5 percent level or better.

Table 1: Endogenously determined Structural Break Dates

\begin{tabular}{|c|c|c|c|}
\hline Countries & Level Shift Date & Trend Shift Date & Trend and Level Shift Date \\
\hline Australia & $\begin{array}{c}\text { April } 1982 \\
\text { December } 1991 \\
\text { May } 1997\end{array}$ & $\begin{array}{c}\text { November } 1991 \\
\text { April } 1997\end{array}$ & $\begin{array}{c}\text { July } 1985 \\
\text { April } 1990 \\
\text { July } 1993 \\
\text { October } 1996 \\
\text { December } 2004 \\
\end{array}$ \\
\hline Canada & $\begin{array}{c}\text { March } 1979 \\
\text { November } 1985\end{array}$ & July 1988 & $\begin{array}{c}\text { December } 1981 \\
\text { December } 1989 \\
\text { March } 1993 \\
\text { July } 1996 \\
\text { June } 2002 \\
\end{array}$ \\
\hline USA & $\begin{array}{c}\text { March } 1954 \\
\text { August } 1958 \\
\text { November } 1961 \\
\text { October } 1973\end{array}$ & $\begin{array}{c}\text { August } 1961 \\
\text { October } 1966 \\
\text { February } 1973\end{array}$ & $\begin{array}{c}\text { June } 1955 \\
\text { January } 1965 \\
\text { January } 1971 \\
\text { August } 1975 \\
\text { November } 1978 \\
\text { December } 1989 \\
\text { October } 1999\end{array}$ \\
\hline
\end{tabular}

Table 2: Lag Selection of ARMA(p,q) process for Disturbances in equation (2) for total LFPR for Australia, Canada and the USA

\begin{tabular}{l|c|c|c|c|c|c}
\hline Countries & $Z_{t}=0$ & $z_{t}=1$ & $Z_{t}=(1, t)^{\prime}$ & $Z_{t}=z_{1 t}$ & $z_{t}=Z_{2 t}$ & $z_{t}=z_{3 t}$ \\
\hline Australia & ARMA(0,2) & ARMA(0,2) & ARMA(1,2) & ARMA(1,1) & ARMA(1,1) & ARMA(0,2) \\
\hline Canada & ARMA(0,3) & ARMA(0,3) & ARMA(1,1) & ARMA(1,1) & ARMA(1,1) & ARMA(1,0) \\
\hline USA & ARMA(0,4) & ARMA(0,4) & ARMA(1,1) & ARMA(1,1) & ARMA(1,3) & ARMA(1,0) \\
\hline
\end{tabular}

We report the values of the one-sided test statistic $\hat{r}$ defined in equation (4) in the parenthesis in Tables 3 based on ARMA estimations. The associated $d_{0}$ values are reported before the parenthesis. In order to save space only those vales of $\hat{r}$ and the associated $d_{0}$ for which the null hypothesis $H_{0}: d=d_{0}$ are not rejected are reported. For the case of $z_{t}=0$ for all the three countries we do not reject the null hypothesis of values of $d$ larger than 1 indicating non-sationarity. For the cases of $z_{t}=1$ and $z_{t}=(1, t)^{\prime}$, which correspond to the cases of a constant and a constant with linear time trend, respectively, the values of $d$ that are not rejected are reduced but still indicate non-stationarity however with mean-reversion. For the 
cases of $z_{1 t}, z_{2 t}$ and $z_{3 t}$, where endogenously determined structural breaks are taken into account indicate further reductions in the values of $d$ under which the null hypothesis are not rejected. In these latter cases the $d$ vales are clearly less than 0.50 indicating that the LFPR series are all stationary for Australia, Canada and the USA. 
Table 3: Testing for Fractional Integration for total LFPR for Australia, Canada and the USA

\begin{tabular}{l|c|c|c|c|c|c}
\hline Countries & $z_{t}=0$ & $z_{t}=1$ & $z_{t}=(1, t)^{\prime}$ & $z_{t}=z_{1 t}$ & $z_{t}=z_{3 t}$ \\
\hline Australia & $\ldots>1^{\mathrm{c}}$ & $0.71^{\mathrm{a}}(0.84) \ldots 0.73^{\mathrm{b}}(-1.26)$ & $0.69^{\mathrm{a}}(1.24) \ldots 0.72^{\mathrm{b}}(-1.56)$ & $0.42^{\mathrm{a}}(1.08) \ldots 0.46^{\mathrm{b}}(-1.40)$ & $0.40^{\mathrm{a}}(1.07) \ldots 0.44^{\mathrm{b}}(-1.39)$ & $0.37^{\mathrm{a}}(1.39) \ldots 0.42^{\mathrm{b}}(-1.44)$ \\
\hline Canada & $\ldots>1^{\mathrm{c}}$ & $0.89^{\mathrm{a}}(1.14) \ldots 0.91^{\mathrm{b}}(-0.88)$ & $0.89^{\mathrm{a}}(1.46) \ldots 0.92^{\mathrm{b}}(-1.63)$ & $0.41^{\mathrm{a}}(1.24) \ldots 0.46^{\mathrm{b}}(-1.52)$ & $0.41^{\mathrm{a}}(1.32) \ldots 0.46^{\mathrm{b}}(-1.45)$ & $0.40^{\mathrm{a}}(1.47) \ldots 0.45^{\mathrm{b}}(-1.25)$ \\
\hline USA & $\ldots>1^{\mathrm{c}}$ & $0.73^{\mathrm{a}}(1.31) \ldots 0.75^{\mathrm{b}}(-1.05)$ & $0.71^{\mathrm{a}}(1.41) \ldots 0.74^{\mathrm{b}}(-1.63)$ & $0.42^{\mathrm{a}}(1.13) \ldots 0.48^{\mathrm{b}}(-1.62)$ & $0.37^{\mathrm{a}}(1.26) \ldots 0.43^{\mathrm{b}}(-1.39)$ & $0.35^{\mathrm{a}}(1.51) \ldots 0.42^{\mathrm{b}}(-1.63)$ \\
\hline
\end{tabular}

\begin{tabular}{l|l|l|c|c|c|c}
\hline USA & $\ldots>1^{\mathrm{c}}$ & $0.73^{\mathrm{a}}(1.31) \ldots 0.75^{\mathrm{b}}(-1.05)$ & $0.71^{\mathrm{a}}(1.41) \ldots 0.74^{\mathrm{b}}(-1.63)$ & $0.42^{\mathrm{a}}(1.13) \ldots 0.48^{\mathrm{b}}(-1.62)$ & $0.37^{\mathrm{a}}(1.26) \ldots 0.43^{\mathrm{b}}(-1.39)$ & $0.35^{\mathrm{a}}(1.51) \ldots 0.42^{\mathrm{b}}(-1.63)$ \\
\hline
\end{tabular}

Notes: Table reports the lower and upper limits of the non-rejection values at the five percent significance levels with corresponding standard normal critical values. ${ }^{\mathrm{a}}$ Lower bound of $d_{0}$ not rejected at the five percent
significance level with corresponding standard normal critical value. ${ }^{\mathrm{b}}$ Upper bound of $d_{0}$ not rejected at the five percent significance level with corresponding standard normal critical value. ${ }^{\mathrm{c}}$ Upper bound of $d_{0}$ not rejected at the five percent significance level is greater than 1. 
Next, we estimate the impulse-response coefficients of the ARFIMA models and the fraction of the time needed for dissipation of the effects of a shock assuming $z_{t}=z_{3 t}$ at the minimum of the LM statistics. For this, we use the generalized impulse responses of Pesaran and Shin (1998) and the measure of persistence $\tau_{\alpha}$ using bootstrap method. We obtained the 95 percent confidence intervals via a parametric bootstrap with 5000 replications. The results are provided in Table 4 and 5. The generalized impulse responses and 95 percent bootstrap confidence intervals for LFPR series are given in Figure 4. These results imply the effects of the shocks are temporary and the series are stationary.

Figure 4: Generalised Impulse-response analysis for Australia, Canada and the USA
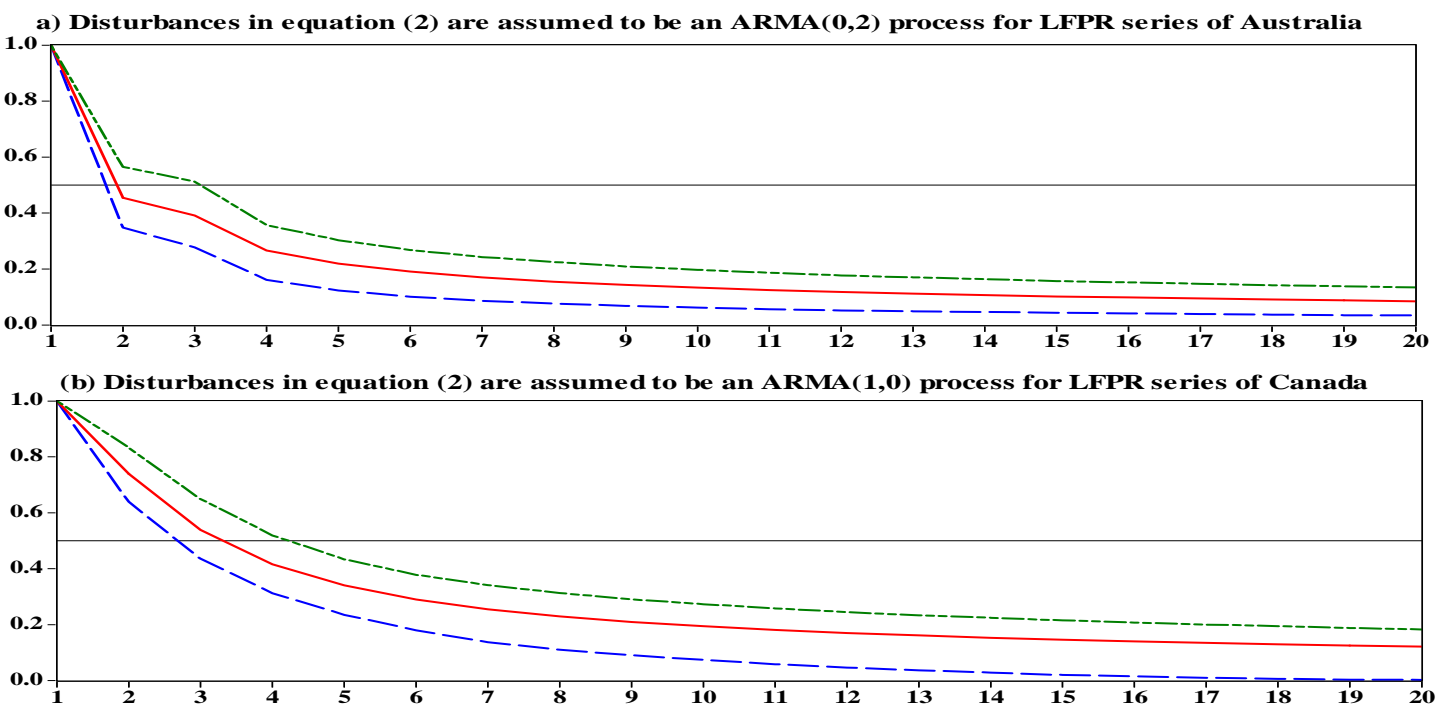

(c) Disturbances in equation (2) are assumed to be an ARMA(1,0) process for LFPR series of USA

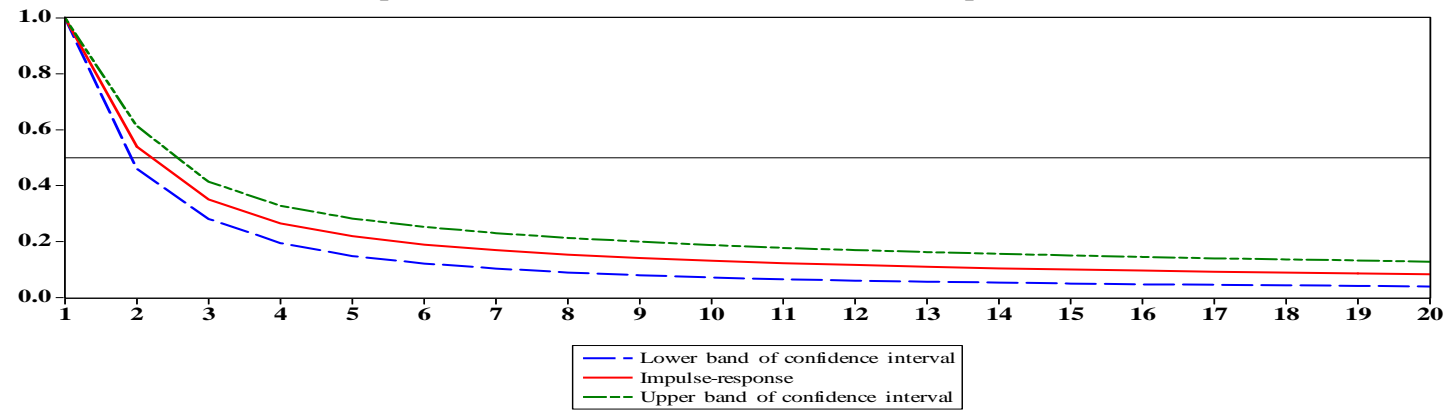

Table 4

$d$ Parameter Estimates Used for Bootstrap Impulse Responses

\begin{tabular}{lccc}
\hline Series & Australia & Canada & USA \\
\hline LFPR & 0.39 & 0.43 & 0.38 \\
\hline
\end{tabular}




\section{Table 5}

Time required for $\alpha$ percent of the full effect of a unit shock to LFPR disappear $\left(\tau_{\alpha}\right)$

\begin{tabular}{lccccc}
\hline Countries & $\alpha=0.30$ & $\alpha=0.50$ & $\alpha=0.80$ & $\alpha=0.90$ & $\alpha=0.95$ \\
\hline Australia & 2 & 2 & 6 & 16 & 47 \\
Canada & 3 & 4 & 11 & 33 & 106 \\
USA & 2 & 3 & 6 & 15 & 44 \\
\hline
\end{tabular}

Notes: Time required is measured in months.

The estimates of $\tau_{\alpha}$ repented in Table 5 show that a period of maximum three months is required for 30 percent of the effects of shocks to disappear. A period of maximum four and eleven months are required, respectively for 50 and 80 percent of the effects of shocks to disappear. Periods longer than one year are required for the 90 and 95 percent of the effects of shocks to disappear. These results imply that all of the LFPR series of these countries are stationary.

\section{Conclusion}

This paper investigates whether the labor force participation rates in Australia, Canada and the USA are stationary. We argue that structural breaks are an important feature of the monthly labor force participation rates series that we consider. Therefore we allow for endogenously multiple structural breaks in both the intercept and slope in the empirical specifications of fractionally integrated processes. We consider $\operatorname{ARMA}(p, q)$ disturbance processes where the lag lengths are empirically determined. The results indicate that the labor force participation rates of Australia, Canada and the USA are stationary. These results are in contrast to the findings of Gustavsson and Österholm (2006) who found that all three series are non-stationary and the finding of Madsen et al. (2008) who found that all three series are mean-reverting. The labor market implications of our findings are as follows. The informational value of the unemployment rates about the behavior of labor markets and the causes of joblessness are useful in Australia, Canada and the USA. In these countries we can talk about one-to-one correspondence between the long-term changes in unemployment rates and the long-term changes in employment rates and that unemployment rate is a useful indicator of joblessness. 


\section{REFERENCES}

Anderson P.,Gustman, A.and Steinmeier, T. 1999. Trends in male labour force participation and retirement: some evidence on the role of pensions and social security in the 1970s and 1980s. Journal of Labor Economics, 17, 757-783.

Australian Bureau of Statistics 2004. Unemployment and participation rates in Australia: a cohort analysis. Australian Economic Indicators, July 2004.

Australian Bureau of Statistics 2008. Explanatory Notes. Labour Force, Australia, July 2008.

Balcilar, M. 1996. Efficient and Near Efficient Unit Root Tests in Models with Structural Change. Ph.D. Dissertation, Wayne State University.

Banerjee, A., Lumsdaine, R.L. and Stock, J.H. 1992. Recursive and sequential tests of the unit-root and trendbreak hypotheses: theory and international evidence. Journal of Business and Economic Statistics, 10, 271287.

Bos, C.; P.H. Franses; and M. Ooms. 1999. Long Memory and Level Shifts: Reanalyzing Inflation Rates. Empirical Economics 24, 427-449.

Clemente, J., Montanes, A. and Reyes, M. 1998. Testing for a unit root in variables with a double change in the mean. Economics Letters, 59, 175-182.

Christiano, L. 1992. Searching for a break in GNP. Journal of Business and Economic Statistics, 10, 237-250.

Dickey, D., and W.A. Fuller. 1979. Distributions of the Estimators for Autoregressive Time Series with a Unit Root. Journal of the American Statistical Association 74, 427-431.

Diebold, F.X., and A. Inoue. 2001. Long Memory and Regime Switching. Journal of Econometrics 105, 131159.

Engle, R.F., and A.D. Smith. 1999. Stochastic Permanent Breaks. Review of Economics and Statistics 81, 553-574.

Gil-Alana, L.A. 1999. Testing of Fractional Integration with Monthly Data. Economic Modelling 16, 613-629. 2001a. A Fractionally Integrated Model with a Mean Shift for the US and the UK Real Oil Prices. Economic Modelling 18, 643-658.

. 2001b. Testing of Stochastic Cycles in Macroeconomic Time Series. Journal of Time Series Analysis 22, 411-430.

2002. Structural Breaks and Fractional Integration in the US Output and Unemployment Rate. Economics Letters 77, 79-84.

Gil-Alana, L.A., and Robinson, P.M. 1997. Testing of Unit Roots and Other Nonstationary Hypotheses in Macroeconomic Time Series. Journal of Econometrics 80, 241-268.

. 2001. Testing of Stochastic Cycles in Macroeconomic Time Series. Journal of Time Series Analysis 22, 411-430.

Gustavsson, M. and Österholm, P. 2006. The Informational Value of Unemployment Statistics: A Note on the Time Series Properties of Participation Rates. Economics Letters, 92, 428-433.

Granger, C.W.J., and Joyeux, R. 1980. An Introduction to Long-Memory Time Series Models and Fractional Differencing. Journal of Time Series Analysis 1, 15-29.

Granger, C.W.J., and Hyung, N. 1999. Occasional Structural Breaks and Long Memory. Department of Economics Working Paper No. 99-4, University of California, San Diego, CA.

Hidalgo, J., and Robinson, P.M. 1996. Testing for Structural Change in Long Memory Environment. Journal of Econometrics 70, 159-174.

Hosking, J. 1981. Fractional Differencing. Biometrika 68, 165-176.

Ingles, D. 2000. Structural ageing, labour market adjustment and the tax/transfer system. Policy Research Paper NO. 5, 1-81, Department of Family and Community Services of Australia.

Kapetanios, G., Shin, Y. and Snell, A. 2003. Testing for a unit root in the nonlinear STAR framework. Journal of Econometrics, 112, 359-379.

Klemes, V. 1974. The Hurst Phenomenon. A Puzzle?. Water Resources Research 10, 675-688.

Künsch, H. 1986. Discrimination between Monotonic Trends and Long-Range Dependence. Journal of Applied Probability 23, 1025-1030.

Lobato, I.N., and Savin, N.E. 1998. Real and Spurious Long Memory Properties of Stock Market Data. Journal of Business and Economic Statistics 16, 261-268.

Lumsdaine, R.L. and Papell, D.H. 1997. Multiple trend breaks and the unit-root hypothesis. Review of Economics and Statistics, 79, 212-218.

Lyons, M. and Smith, M. 2008. Gender Pay Equity, Wage Fixation and Work Choices: Forward to the Past?. mimeo. University of Western Sydney.

Madsen J., Mishra V. and Smyth R. (2008) “Are Labour Force Participation Rates Non-Stationary? Evidence From 130 Years for G7 Countries”, Australian Economic Papers, 47, 166-189.

Mosisa, A. and Hipple, S. 2006. Trends in labor force participation in the United States. Monthly Labor Review, Vol.129, No:10, 35-57. 
Murphy, K.M. and Topel, R. 1997. Unemployment and nonemployment. American Economic Review, 87, 295300.

Ohara, H.I. 1999. A unit root test with multiple trend breaks: a theory with an application to US and Japanese macroeconomic time series. Japanese Economic Review, 50, 266-290.

Ozdemir, Z.A., Balcilar, M., and Tansel, A (2012) "International Labour Force Participation Rates by Gender: Unit Root or Structural Breaks?”, Bulletin of Economic Research, 0307-3378, DOI: 10.1111/j.14678586.2011.00419.x.

Perron, P. 1989. The Great Crash, the Oil-Price Shock, and the Unit Root Hypothesis. Econometrica 57, 13611401.

Perron, P. and Vogelsang, T.J. 1992. Nonstationarity and level shifts with an application to purchasing power parity. Journal of Business and Economic Statistics, 10, 301-320.

Phillips, P.C.B., and P. Perron. 1988. Testing for a Unit Root in a Time Series Regression. Biometrika 75, 335346.

Robinson, P.M. 1994. Efficient Tests of Nonstationary Hypotheses. Journal of the American Statistical Association 89, 1420-1437.

Statistics Canada, 2006. The Canadian Labour Market at a Glance, Labour Statistics Division. Catalogue no. 71-222-XIE. Ottawa.

Teverovsky, V., and M.S. Taqqu. 1997. "Testing for Long Range Dependence in the Presence of Shifting Means or a Slowly Declining Trend, Using a Variance-Type Estimator.” Journal of Time Series Analysis 18, 279304.

Toossi, M. 2002. “A century of change: the U.S. labor force, 1950-2050”, Monthly Labor Review, Vol.125, No:5, 15-28.

Zivot, E. and Andrews, D.W.K. 1992. Further evidence on the great crash, the oil price shock, and the unit root hypothesis. Journal of Business and Economic Statistics, 10, 251-270.

Whittle, P. 1951. Hypothesis Testing in Time Series Analysis. Uppsala: Almqvist and Wiksells. 